\title{
MONITORAMENTO AMBIENTAL NA ZONA DE AMORTECIMENTO DO PARQUE ESTADUAL DE PORTO FERREIRA, PORTO FERREIRA - SP.
}

\author{
André Luis Teixeira De Lucca ${ }^{1}$ \\ Ernesto Pedro Dickfeldt ${ }^{2}$ \\ Sonia Aparecida de Souza Evangelista ${ }^{3}$
}

\section{RESUMO}

Atividades de monitoramento ambiental foram implantadas na Zona de Amortecimento do Parque Estadual de Porto Ferreira com o objetivo de identificar ações antrópicas conflitantes e buscar a minimização dos seus efeitos negativos. Entre os anos de 2006 a 1015 foram identificadas 26 ações conflitantes em relação à flora, fauna, solo, recursos hídricos e ar. O apoio do Conselho Consultivo contribuiu com discussões e encaminhamentos na perspectiva de favorecer a manutenção dos processos ecológicos, a adequação e a sustentabilidade ambiental na região da unidade de conservação.

PALAVRAS-CHAVE: Uso do Solo. Ações Antrópicas. Plano de Manejo.

\section{INTRODUÇÃO}

A Zona de Amortecimento é definida com o entorno de uma unidade de conservação onde as atividades humanas estão sujeitas a normas e restrições específicas, com o propósito de minimizar os impactos negativos sobre elas. Essa zona pode ser definida pelo Plano de Manejo, considerando os resultados dos estudos, a caracterização do meio biofísico e dos aspectos socioeconômicos da região onde está inserida a unidade (BRASIL, 2000).

\footnotetext{
${ }^{1}$ Instituto Florestal e Fundação Florestal - andrelucca1@yahoo.com.br

2 Instituto Florestal e Fundação Florestal - epdic@ig.com.br; ernesto.dickfeldt@terra.com.br

${ }^{3}$ Instituto Florestal e Fundação Florestal - soniasouza@if.sp.gov.br; ssouza@fflorestal.sp.gov.br
} 
No contexto das unidades de conservação de proteção integral do interior do Estado de São Paulo, destaca-se o Parque Estadual de Porto Ferreira - PEPF que conserva amostras representativas da floresta estacional semidecidual e do cerrado, além de $5 \mathrm{~km}$ de mata ciliar ao longo do rio Mogi Guaçu.

Durante a elaboração do Plano de Manejo do PEPF entre os anos de 2002 e 2003, estudos sobre a biodiversidade, o meio biofísico e o uso do solo salientaram a influência direta das microbacias em relação à unidade e assim, os interflúvios das microbacias do ribeirão dos Patos e do córrego da Água Parada delimitam a Zona de Amortecimento da unidade (TABANEZ et al., 2003). Para essa zona foram definidos o subprograma de monitoramento ambiental e o programa de controle ambiental.

De acordo com o inciso VIII do Art. 20 do Decreto n 4.340 , de 22 de agosto de 2002 compete ao conselho consultivo a manifestação sobre obra ou atividade potencialmente causadora de impacto na unidade de conservação, em sua zona de amortecimento, mosaicos ou corredores ecológicos (Brasil, 2002).

Assim, considerando o uso do solo conflitante na Zona de Amortecimento ZA do PEPF, a partir de 2006 foram desenvolvidas atividades de monitoramento ambiental em atendimento ao Plano de Manejo da unidade, onde os encaminhamentos contaram com o apoio do Conselho Consultivo.

\section{OBJETIVOS}

- Desenvolver ações de monitoramento ambiental na Zona de Amortecimento do PEPF, identificando atividades antrópicas conflitantes, e

- promover os encaminhamentos visando à manutenção dos processos ecológicos, a adequação e a sustentabilidade ambiental.

\section{METODOLOGIA}

\section{1 Área de estudo}

O Parque Estadual de Porto Ferreira localiza-se no município de Porto Ferreira, região nordeste do Estado de São Paulo, com uma área de 611,55 ha. 
A ZA do PEPF, conta com área de 5.277,13 ha tendo como limite ao norte, leste e oeste os interflúvios das bacias hidrográficas do ribeirão dos Patos e do córrego da Água Parada, que drenam para a unidade de conservação. Ao sul e sudoeste há uma franja na margem esquerda oposta ao rio Mogi Guaçu confrontante ao Parque, englobando as planícies fluviais de entorno imediato (TABANEZ et al., 2003).

A Figura 1 apresenta o zoneamento do PEPF, destacando a ZA.

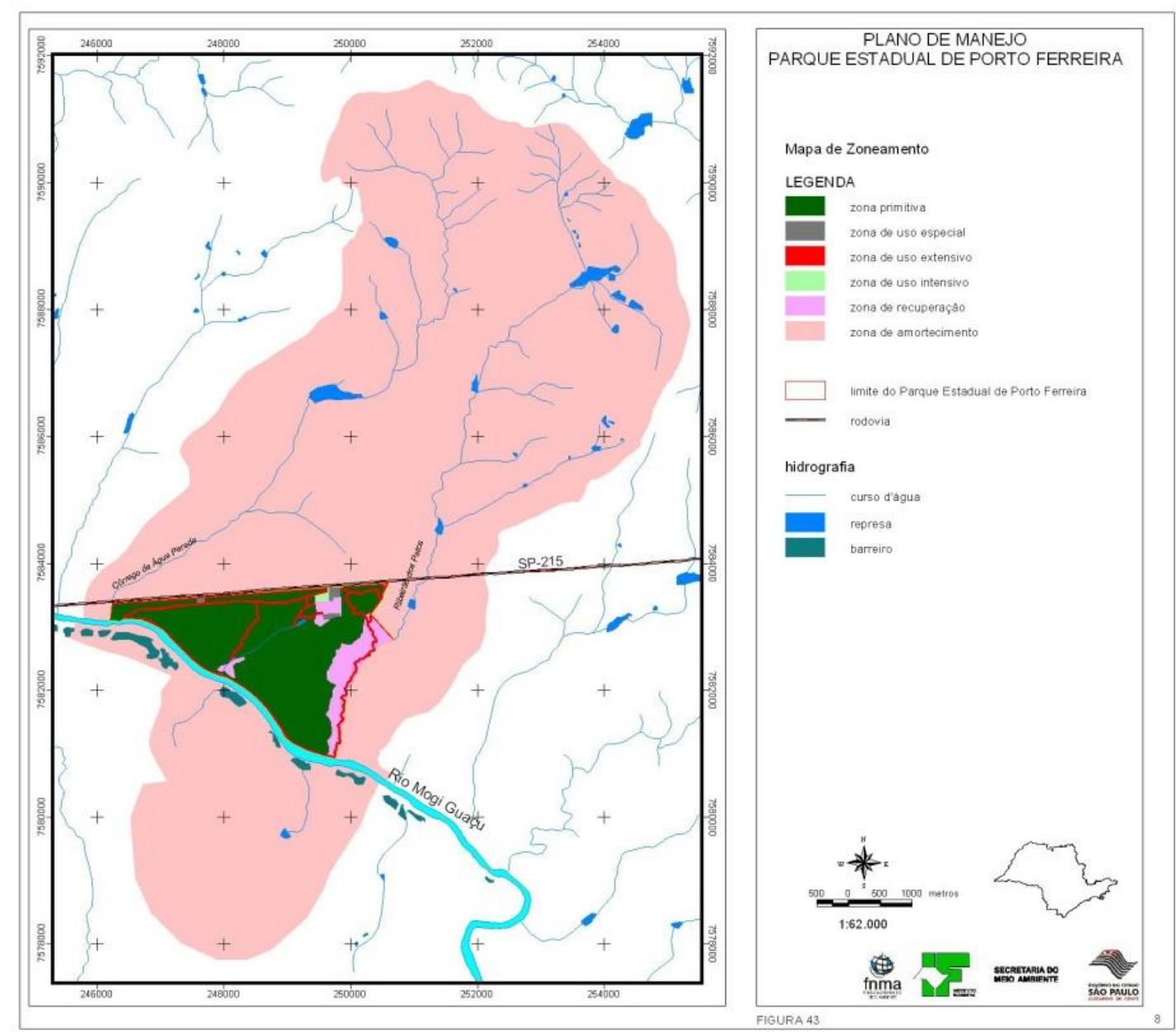

Figura 1. Mapa de Zoneamento do PEPF - ZA em rosa.

Fonte: Tabanez et al. (2003)

\subsection{0 monitoramento ambiental}

A partir da aprovação do Plano de Manejo em 2006 foram sistematizadas e implementadas as ações de monitoramento na ZA do PEPF. 
Para tanto, foi definida a estratégia de saída a campo semanal por dois técnicos do Parque para identificar as atividades conflitantes, tendo com base o Plano de Manejo, a legislação ambiental e outros instrumentos e normas pertinentes ao contexto local.

\section{RESULTADOS E DISCUSSÃO}

Entre os anos de 2006 a 2015 durante as atividades de monitoramento ambiental do PEPF foram identificadas 27 ações antrópicas conflitantes na ZA do PEPF, conforme apresenta a Tabela 1.

Tabela 1. Relação das ações antrópicas conflitantes na ZA do PEPF e principais indicadores.

$\begin{array}{cc}\text { Meio afetado/ } & \text { Indicadores } \\ \text { ação antrópica } & \end{array}$

Flora

Corte de vegetação nativa em APP

Incêndios florestais criminosos e acidentais

Extrativismo irregular da vegetação nativa

Manejo insuficiente de fragmentos florestais

\section{Fauna}

Caça

Pesca predatória

Atropelamento de animais silvestres na Rodovia SP-215 confrontante ao PEPF Instalação de cercas de arame farpado

Aplicação de pesticidas em culturas com efeitos danosos à fauna
Ausência e/ou descontinuidade de mata ciliar Focos de incêndios e vegetação queimada, presença de materiais de rituais religiosos (velas)

Corte de palmitos e de arbustos para confecção de ferramentas

Presença de lianas e proliferação de gramíneas exóticas

Presença de cevas, vestígios e denuncias

Presença de covos, estaleiros e redes nos cursos d'água

Animais atropelados

Animais feridos, presença de pelos nas farpas das cercas

Morte de aves e abelhas 


\section{Solo}

Manejo inadequado do solo

Produção em sistema de monocultura

Aplicação de agrotóxicos

Descarte irregular de embalagens de agrotóxicos

Fertirrigação com uso de vinhaça

Cultivo de transgênicos

Descarte irregular de resíduos sólidos urbanos

Esgoto lançado "in natura"

Estradas sem conservação

Recursos hídricos

Esgoto lançado "in natura"

Lançamento de efluentes no rio Mogi Guaçu

Barramento de cursos d'água

Irrigação descontrolada

Falta de APP

$\mathrm{Ar}$

Pulverizações agrícolas com aviões e tratores

Queimadas

\section{Outros}

Linhas de transmissão de energia elétrica
Erosão, sedimentos e turbidez dos cursos d'água e presença de gado em APP

Predomínio de cultura de cana-de-açúcar

Presença de agrotóxico granulado exposto no solo

Presença de embalagens expostas na ZA

Bacias de depósito, tubulações de aplicação e odor característico

Placas indicativas de variedades transgênicas

Presença de lixo nas estradas, nas bordas dos remanescentes florestais, entre as culturas e dentro de antigas cavas de mineração

Valas com efluentes domésticos e mau cheiro

Poeira, lama e erosão

Água turva, mau cheiro e presença de tubos em barrancos e análises químicas

Espuma e mortalidade de peixes

Construção de barragens improvisadas

Vazamentos nas tubulações, sistemas pouco eficientes

Ausência de mata ciliar, plantios e processos erosivos

Deriva de gotículas de pesticidas, de maturadores e área de pouso de avião

Fumaça, fuligem, morte de animais silvestres e domésticos

Presença de várias linhas e acidentes com a fauna

A partir de 2010 as ações antrópicas conflitantes passaram a compor a pauta das reuniões do Conselho Consultivo, buscando assim o apoio das instituições governamentais e da sociedade civil para a minimização dos efeitos negativos em relação ao PEPF e ao meio ambiente.

As Figuras de 1 a 8 ilustram algumas atividades conflitantes na ZA do PEPF. 
Figura 1. Plantio morro abaixo

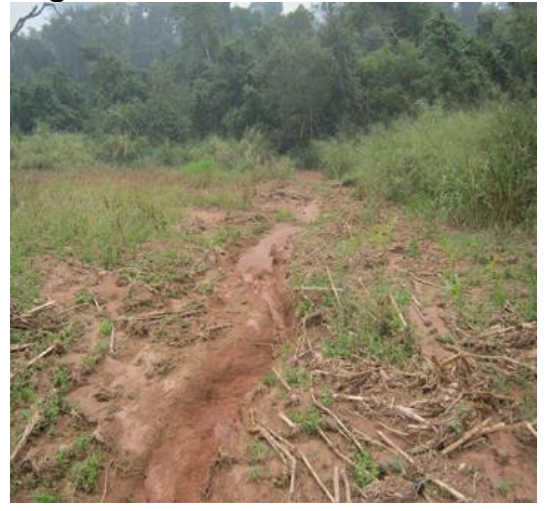

Figura 3. Descarte indevido de embalagem.

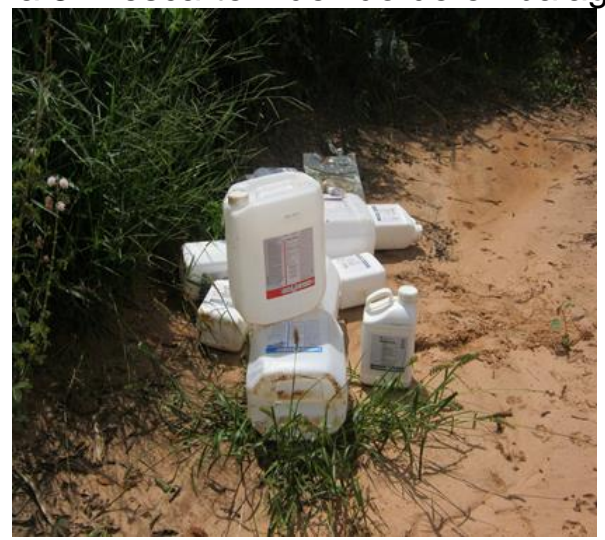

Figura 5. Atropelamento na Rodovia SP-215 confrontante ao PEPF.

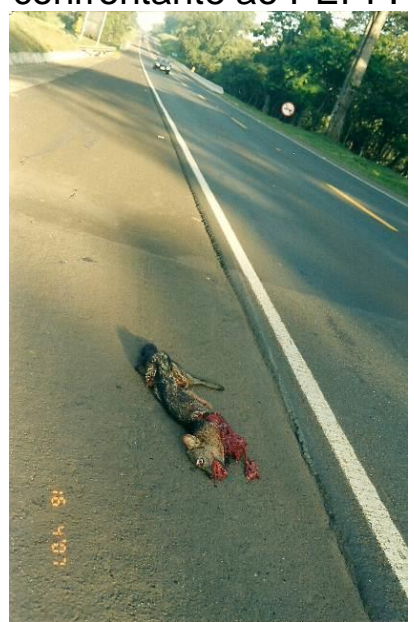

Figura 2. Depósito de vinhaça.

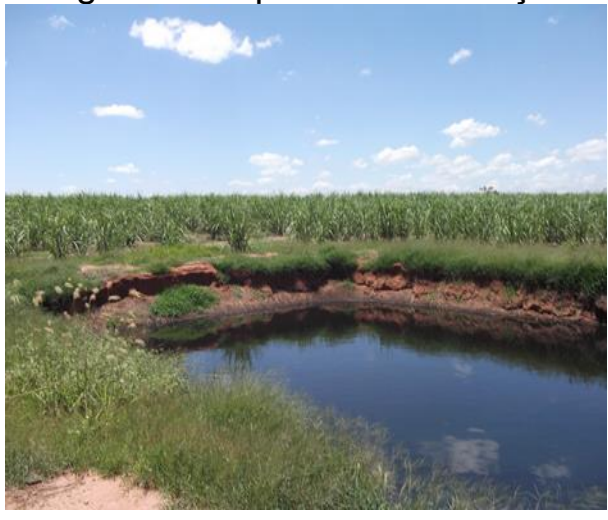

Figura 4. Pulverização aérea.

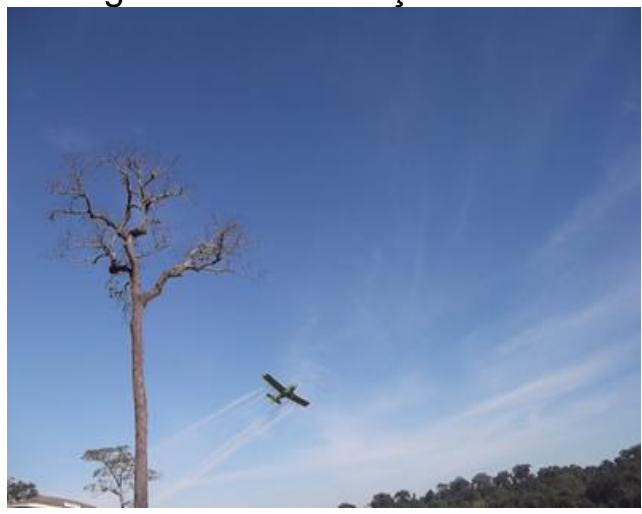

Figura 6. Girau encontrado na ZA.

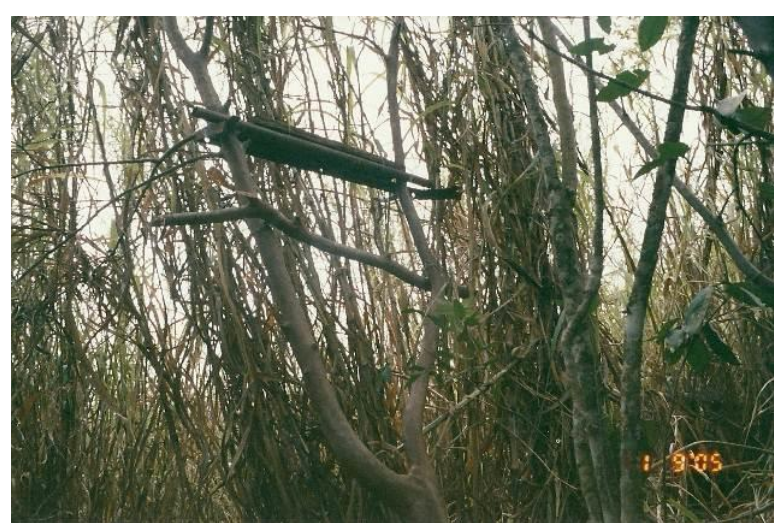


Figura 7. Depósito indevido de resíduos sólidos na ZA.

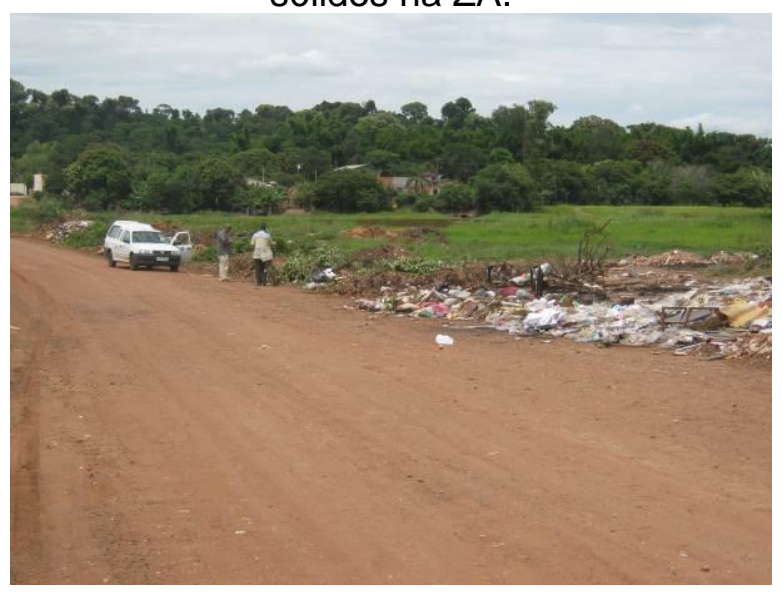

Figura 8. Linhão de energia, área queimada.

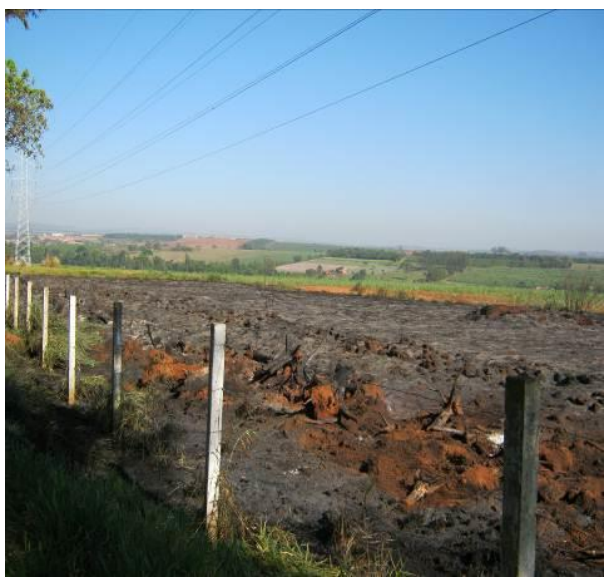

Em relação à flora, quando identificadas ações conflitantes é acionada a Polícia Ambiental.

Para a falta de Áreas de Preservação Permanente - APP foi elaborado um projeto pela equipe do PEPF para diagnóstico e proposta de recuperação florestal nas microbacias da ZA. Outra ação pró-ativa foi a indicação de áreas prioritárias ao empreendimento SEDA - Sistema de Escoamento Dutoviário de Álcool e Derivados que efetuou uma compensação ambiental com a recuperação florestal em cerca de 30 hectares distribuídos em 04 propriedades rurais na ZA. Essa ação contou com o apoio do Engํำ Agrônomo responsável pela Casa da Agricultura.

A presença de gramíneas exóticas e o depósito de resíduos sólidos também contribuem com a degradação de fragmentos florestais na ZA.

Quanto à fauna, a caça é uma prática cultural que ainda existe na região do PEPF. Vestígios como animais mortos, giraus, armadilhas e instrumentos de caça são encontrados durantes as atividades de fiscalização e monitoramento. A Polícia Ambiental é acionada após identificação de vestígios na unidade e na ZA.

Em relação à pesca, as diferentes modalidades com uso de vara, rede e covo são predatórias para a ictiofauna, atingindo ainda alguns mamíferos de hábitos também aquáticos. Contatos com proprietários rurais são realizados para alertá-los quanto à invasão de pessoas estranhas para as práticas de caça e pesca na ZA.

O monitoramento dos animais silvestres atropelados na Rodovia SP-215 confrontante ao Parque foi realizado sistematicamente entre os anos de 2003 a 2009 verificando a grande incidência sobre os mamíferos. Os dados gerados foram 
apresentados à concessionária com solicitação de medidas mitigadoras de redução de velocidade, implantação de radar fotográfico e outras, no entanto, as mesmas ainda não foram implantadas.

Para os encaminhamentos de animais silvestres feridos, resgatados e abandonados na ZA, a Polícia Ambiental e o Zoológico de São Carlos são instituições parceiras que atende as demandas do Parque.

A presença de animais exóticos como a Lebre européia Lepus europaeus, e relatos da chegada do Javali Sus scrofa merecem atenção, uma vez que a presença desses animais podem ameaçar os animais silvestres que utilizam também os fragmentos florestais da região como área de vida.

Em relação ao solo foi observado o manejo inadequado em algumas culturas como, por exemplo, o plantio "morro abaixo" que causou erosão laminar superficial e carreamento para o ribeirão dos Patos no limite leste com o Parque. Para minimizar tal impacto foi acionado o órgão de defesa da Secretaria da Agricultura que notificou a propriedade indicando medidas para a adequação do plantio.

Contatos com os proprietários rurais são realizados para alertar o uso inadequado de agrotóxicos, na perspectiva de evitar a exposição no solo e possíveis contaminações dos recursos hídricos, além do risco à fauna.

Quanto às culturas da cana-de-açúcar, a equipe do Parque alerta, ressalta e orienta sobre a necessidade de atendimento à legislação ambiental referente a queima, depósitos de vinhaça, estabelecimento de aceiros, uso de APP e pulverização aérea. A eliminação de alguns depósitos é resultado desse trabalho.

Quando verificado o descarte irregular de resíduos sólidos na ZA, principalmente em antigas cavas de mineração é acionado setor de fiscalização da Prefeitura Municipal de Porto Ferreira e a CETESB - Companhia Ambiental do Estado de São Paulo.

Em relação aos recursos hídricos, consultas e encaminhamentos para a Policia Ambiental, CETESB e ICMBio são frequentes, principalmente em relação à poluição, supressão da vegetação em APP e práticas de caça e pesca predatória às margens do rio Mogi Guaçu, ribeirão dos Patos e córrego da Água Parada.

Quanto à pulverização aérea, a equipe do Parque estabelece contato com os proprietários e técnicos responsáveis das empresas para alertá-los quanto as operações próximas à unidade e aos recursos hídricos da ZA. Inferimos que as 
partículas ou aerossóis dos agrotóxicos, pesticidas e maturadores em deriva pelo vento, podem afetar a fenologia das espécies vegetais e a cadeia alimentar, além dos riscos à população da região.

Para a instalação das linhas de transmissão de energia elétrica houve a supressão da vegetação, e esse fato contribuiu com o processo de fragmentação florestal, além de interferir na paisagem natural da região; no entanto, as mesmas foram implantadas antes da elaboração do Plano de Manejo e da definição da ZA.

Outra ação antrópica na ZA é a construção de cercas de arame farpado, que podem ferir animais silvestres de médio e grande porte. Essa ação foi discutida com a Concessionária da Rodovia SP-215 que justificou a instalação da cerca para prevenir acidentes com os animais domésticos.

\section{CONSIDERAÇÕES}

O estabelecimento das atividades de monitoramento ambiental de forma sistemática contribuiu para a identificação de ações antrópicas conflitantes na ZA do PEPF, com orientação e esclarecimentos visando à adequação ambiental.

A maioria das ações foi discutida em reuniões do Conselho Consultivo que contribuiu com encaminhamentos visando à mitigação de impactos ambientais na ZA e consequentemente no interior da unidade de conservação.

Neste sentido, a continuidade do monitoramento ambiental tende favorecer a manutenção os processos ecológicos, a adequação e a sustentabilidade ambiental na região do PEPF.

\section{REFERÊNCIAS}

BRASIL. Lei no 9.985, de 18 de julho de 2000. Dispõe sobre o Sistema Nacional de Unidades de Conservação da Natureza (SNUC). Brasília, DF: MMA/SBF, 2000. 32 p.

BRASIL. Decreto oㅜ 4340, de 22 de agosto de 2002. Disponível em: <http://www.planalto.gov.br/ccivil_03/decreto/2002/D4340.htm>. Acesso em: 27 mar. 2010.

TABANEZ, Marlene Francisca et al. Plano de Manejo do Parque Estadual de Porto Ferreira. São Paulo: $\mathrm{O}_{2}$ Estúdio Web, 2003. 1 CD-ROM. 